\title{
Avaliação de Beneficiárias Ribeirinhas da Amazônia sobre o Programa Bolsa Família
}

\author{
Thamyris Maués dos Santos ${ }^{1}$ \\ Simone Souza da Costa Silva \\ Universidade Federal do Pará \\ Silvia Helena Koller \\ Universidade Federal do Rio Grande do Sul
}

\begin{abstract}
RESUMO - O objetivo deste artigo é descrever a avaliação de mães ribeirinhas amazônicas beneficiárias do Programa Bolsa Família sobre sua participação no programa. Portanto, realizou-se um estudo qualitativo com quatro mães moradoras de uma ilha Combú, pertencente ao município de Belém (PA), que participavam do Programa Bolsa Família. Um questionário sociodemográfico e uma entrevista semiestrutrada foram aplicados para compreender como essas mães avaliavam sua vida antes e após a participação no programa. Os resultados sugerem mudanças ocorridas após a inserção no programa, como a diminuição da dependência à renda do marido, maior planejamento na realização dos gastos e a atual inexistência de situações nas quais não houvesse alimento. O programa possui uma importância concreta na organização econômica das famílias, proporcionando maior senso de segurança e estabilidade.
\end{abstract}

Palavras-Chave: Programa Bolsa Família, programas sociais, famílias ribeirinhas, Amazônia, Brazil

\section{Evaluation of Amazon Riverine Beneficiaries about Bolsa Família Program}

\begin{abstract}
The purpose of this article is to describe the evaluation of mothers who receive a Family Grand (Bolsa Família) living in a riverside community in the Amazon on participation in the program. Therefore a qualitative study was conducted with four mothers, residents of the island Combú belonging to the municipality of Belém (PA), who participated in the Family Grand program. A sociodemographic questionnaire and a semi-structured interview were applied to understand how the mothers perceived their life before and after the program. The results showed perceptual changes after the insertion in the program in the sense that the mothers no longer perceived themselves as highly dependent on their husband's income, while the expenditures were realized in a more planned way and the occurrence of situations in which there was no food ceased to exist. The program has a concrete importance in the economic organization of families, providing greater sense of security and stability.
\end{abstract}

Keywords: Bolsa Família Program, social programs, riverine families, Amazon Region, Brazil

Este estudo descreve a avaliação de mães beneficiárias do Programa Bolsa Família (PBF), moradoras de uma comunidade ribeirinha amazônica, sobre a participação no programa. O PBF é uma política social que busca a redução da pobreza e a minimização da desigualdade social (Haddad, 2008). Para alcançar esses objetivos, o governo federal realiza a transferência direta de renda com condicionalidades, beneficiando famílias pobres e extremamente pobres de todo o país. Os benefícios monetários são concedidos mensalmente às famílias e variam de acordo com a renda per capita e a quantidade de crianças, adolescentes, gestantes e nutrizes. Para que possam ser inseridas como beneficiárias, é necessário que as famílias inscrevam-se no Cadastro Único do Governo Federal e, após serem selecionadas, cumpram condicionalidades nos campos da educação, da saúde e da assistência social (Ministério do Desenvolvimento Social e Combate à Fome [MDS], 2012).

1 Endereço para correspondência: Universidade Federal do Pará, Passagem Salvador, 75, Telégrafo, Belém, PA, Brasil. CEP: 66.113210.E-mail: thamymaues7@yahoo.com.br
No tocante à educação, cada criança de seis a 15 anos deve apresentar o mínimo de $85 \%$ de frequência escolar e cada jovem de 16 e 17 anos deve apresentar ao menos $75 \%$ de frequência escolar. Na área de saúde, por sua vez, as crianças menores de sete anos devem ser vacinadas e acompanhadas em postos de saúde, enquanto as mulheres gestantes ou lactantes da família devem fazer o acompanhamento médico. Já na área da assistência social, crianças e adolescentes de até 15 anos que estejam em risco ou tenham sido retirados do trabalho infantil pelo Programa de Erradicação do Trabalho Infantil (PETI) devem participar dos Serviços de Convivência e Fortalecimento de Vínculos e das atividades do PETI, bem como obter frequência mínima mensal de $85 \%$ nessas atividades (MDS, 2012).

O impacto do PBF nas áreas da desigualdade, pobreza, consumo, educação, saúde e participação na força de trabalho foi comparado a programas semelhantes de outros países da América Latina (Soares, Ribas, \& Osório, 2010). Com relação aos impactos socioeconômicos do PBF, o programa não parece ter afetado significativamente o nível agregado de consumo familiar. Porém, demonstrou-se que 
os gastos específicos com alimentos, educação e roupas infantis aumentaram. Tal resultado é consoante com os dados apontados em um estudo com famílias holandesas beneficiárias de programas públicos de transferência de renda, no qual foi demonstrado que as famílias utilizavam a nova fonte de renda com gastos que beneficiassem diretamente as crianças (Kooreman, 2000). O direcionamento especial desses gastos pode estar relacionado à provável percepção dos pais de que o benefício é propriedade eminente das crianças.

Os índices de redução da desigualdade social também foram avaliados, sendo que segundo Soares et al. (2010), o coeficiente de Gini, que mede o grau de desigualdade existente na distribuição de indivíduos segundo a renda domiciliar per capita, caiu 4,7\% no Brasil, de 1995 a 2004. Os programas de transferência condicionada de renda, como o PBF, foram responsáveis por $21 \%$ desse total, sendo a segunda fonte de renda mais importante para diminuir tal índice, vindo após os ganhos oriundos do trabalho. De maneira geral, os programas de transferência condicionada de renda têm um impacto significativo na renda de famílias que passam por situações de precariedade financeira. O PBF foi responsável pela redução de $12 \%$ da pobreza e de $19 \%$ da pobreza severa no país, sendo que, para os 5\% mais pobres, as transferências representam $10 \%$ ou mais de sua renda total. Consequentemente, o PBF tem exercido um impacto notável na redução da desigualdade social, embora esta não seja uma de suas metas. (Soares et al., 2010).

Contudo, Haddad (2008) considera que o crescimento econômico, por si só, não seria suficiente para resolver os problemas sociais, podendo inclusive aumentar a desigualdade entre as pessoas. Essa perspectiva é concernente à visão do Programa das Nações Unidas para o Desenvolvimento (PNUD, 2010), que concebe que a melhor forma de elevar os padrões de vida e erradicar a pobreza mundial seria unir desenvolvimento econômico com políticas sociais direcionadas especificamente à diminuição da pobreza.

Além das análises quantitativas utilizadas eminentemente pela literatura econômica para medir o impacto de um programa com a magnitude do PBF, outra forma importante de avaliá-lo é através da investigação das perspectivas individuais. A importância de considerar a forma como um programa social é percebido pelos indivíduos justifica-se pela possibilidade de inferir estimativas de eficiência e de eficácia de tal programa, bem como de consequentemente reavaliar suas formas de implantação e atuação (Castro, Walter, Santana, \& Stephanou, 2009). Além do mais, no caso do $\mathrm{PBF}$, a forma como o benefício é percebido direciona a forma como o dinheiro será gasto, pois restrições e possibilidades são impostas de acordo com o significado atribuído a essa fonte de renda.

De maneira geral, a população brasileira conhece o PBF e entende que os principais objetivos (de combate à pobreza, de manutenção da criança na escola e de redução do trabalho infantil) estão sendo atingidos (Castro et al., 2009). Além disso, $72 \%$ dos participantes da pesquisa desenvolvida por Castro et al. (2009) consideraram que o PBF traz bons resultados para o país, sendo que esse percentual foi ainda maior entre aqueles que conhecem algum beneficiário (77\%).
No município de Belém, em julho de 2014, havia 154.656 famílias registradas no Cadastro Único e 101.385 famílias beneficiárias do PBF, o que corresponde a 21,78\% da população do município e a 105,47 \% do total estimado de famílias do município com perfil de renda do programa. Em março de 2013, o benefício do Brasil Carinhoso, inicialmente pago a famílias extremamente pobres com filhos de 0 a 15 anos, foi estendido a todas as famílias do PBF. Com a mudança, todas as famílias do programa superam a extrema pobreza. (MDS, 2014)

No que diz respeito ao cumprimento das condicionalidades do PBF no município, 95,03\% das crianças e jovens de 6 a 17 anos do PBF atenderam os critérios de frequência escolar mínima, sendo que a média nacional é de 92,03\%, de modo que o município está acima da média. Na área da saúde, o acompanhamento chega a 33,03 \% das famílias com perfil, ou seja, aquelas com crianças de até sete anos e/ou com gestantes, sendo que a média nacional é de 73,44\%, estando o município muito abaixo dessa média (MDS, 2014).

No que diz respeito à avaliação sobre o PBF de mulheres beneficiárias residentes em Campinas, um município urbanizado do estado de São Paulo, Pires (2008) destaca dois elementos fundamentais. Em primeiro lugar, o benefício é visto como uma "ajuda", sendo que tal percepção estaria associada ao fato de as participantes do estudo serem moradoras de uma cidade "na qual as oportunidades para se obter rendimentos provenientes do trabalho (...) são aparentemente maiores do que em outras localidades" (p.137). Consequentemente, o dinheiro do benefício não ocuparia uma posição central na renda familiar total. Além do mais, o benefício é visto como um dinheiro fundamentalmente feminino e carregado de moralidade, sendo que poderia ser utilizado de forma "correta", ou seja, gasto com produtos ou serviços que beneficiem principalmente as crianças, ou "errada", sendo gasto com bebidas e produtos utilizados apenas pelos pais.

Uma vez que a maioria dos estudos realizados acerca do PBF é produzida nas áreas de Economia e Ciências Sociais, tornam-se necessários estudos que enfatizem a avaliação dos beneficiários, sendo esta a principal contribuição da Psicologia, em especial da Psicologia Econômica. A Psicologia Econômica é uma área de interface da Psicologia e da Economia focada especificamente na negociação dos recursos escassos de que os seres humanos dispõem, como dinheiro, tempo e esforços (van Raaij, 1999). De acordo com Ferreira (2008), a Psicologia Econômica pode ser definida como uma tentativa de compreender as decisões humanas a respeito do uso de recursos escassos, a partir de modelos econômicos descritivos, e não normativos, como faz a Economia.

Os recursos escassos e finitos, cujo uso denota a necessidade de o agente econômico fazer escolhas, levam os indivíduos a tomarem decisões econômicas. De acordo com Kahneman (2012), os processos de tomada de decisão são atos complexos que envolvem elementos da percepção e da avaliação pessoal sobre qual a melhor escolha a ser tomada em determinada situação.

Porém, a percepção dos indivíduos acerca das situações que vivenciam varia de acordo com as informações disponíveis, ou seja, de acordo com o contexto. Segundo 
Kirchler (1999), "decisões econômicas e não econômicas em domicílios devem ser consideradas em seu contexto geral. (...) As dinâmicas das decisões podem apenas ser adequadamente compreendidas se estudadas sobre a base de uma variedade de atividades que ocorrem simultaneamente" (p. 297). Considerando essa perspectiva, faz-se necessário identificar aspectos do ambiente econômico e social dos beneficiários do PBF que sejam relevantes para a forma como percebem o benefício e como gastam o mesmo.

Uma vez que o PBF possui amplitude nacional, o modo como é avaliado pelos beneficiários é diverso e varia de acordo com o local em que os mesmos residem. As influências contextuais podem alterar a forma como o benefício é visto e como será utilizado, além da importância que o mesmo terá na renda familiar total. Desse modo, é fundamental conhecer as percepções oriundas de contextos peculiares, como comunidades localizadas às margens de rios na Amazônia.

Dada a prevalência da população brasileira nas grandes cidades, a maioria das pesquisas realiza-se nos ambientes urbanos. Porém, os meios rurais concentram $25 \%$ da população brasileira (Albuquerque, 2002) e uma das regiões que apresenta maior concentração populacional de pessoas vivendo em ambientes rurais é a Amazônia.

De acordo com Lima e Pozzobon (2005), existem nove categorias socioambientais de produtores rurais residentes na Amazônia, sendo uma delas os pequenos produtores "tradicionais", grupo no qual se inserem os ribeirinhos. Os pequenos produtores "tradicionais" são os habitantes da Amazônia originários do processo de colonização ibérica da região. Apresentam eminentemente uma economia de subsistência, ou seja, sua produção é realizada principalmente para consumo próprio. Ainda que tenham exercido várias funções, como coletores, pescadores ou agricultores, receberam de forma impositiva um padrão cultural de consumo de artigos manufaturados, na medida em que vislumbravam a possibilidade de serem inseridos em um mundo "civilizado".

Os ribeirinhos amazônicos dependem do rio como principal espaço de sustentação e de formação de sua identidade, sendo que muitas comunidades ribeirinhas apresentam como principal característica o isolamento físico e social em relação a outras comunidades, o que também torna escassos os recursos de que possam dispor (Silva, Pontes, Lima, \& Maluschke, 2010; Silva, Pontes, Santos et al., 2010). Porém, viver às margens do rio não é suficiente para caracterizar uma população como ribeirinha. $\mathrm{Na}$ Amazônia, muitas cidades foram formadas há mais de 300 anos, a partir de atividades realizadas através do rio. No entanto, paulatinamente perderam essa característica, tornando-se cada vez mais dependentes dos meios terrestres para realizar suas atividades, como é o caso de Belém e Manaus (Cruz, 2008).

Especificamente em Belém, apesar de sua orientação urbana que segue o padrão de utilização de vias terrestres para locomoção, a maior parte da área geográfica do município é composta por ilhas (Secretaria Municipal de Coordenação Geral do Planejamento e Gestão [SEGEP], 2011). De acordo com Reis, Araújo, Santos, Silva e Pontes (2012), a proximidade geográfica das ilhas à metrópole é um dos grandes diferenciais nas análises de comunidades ditas "tradicionais", afetando questões de modo de vida, como a participação no mercado de trabalho da área urbana de Belém, o fácil acesso a meios de comunicação de massa, como televisão e internet, e disponibilidade de serviços nas áreas de saúde e educação, de mais difícil acesso para comunidades ribeirinhas isoladas.

A forma de produção econômica dos ribeirinhos é geralmente "orientada pelas demandas de consumo doméstico, produzida em bases familiares, 'avessa' aos riscos, não contábil, fortemente dependente das imposições da natureza, direcionada ao mercado para a troca de bens necessários à sua sobrevivência e bens "supérfluos"” (Moura, Nascimento, \& Côrrea, 2007, p. 520). Uma vez que sua produção existe principalmente em função das demandas do grupo ao qual pertencem, é comum que os ribeirinhos não produzam bens com o objetivo de obter lucro. Mesmo quando realizam trocas comerciais, os ribeirinhos costumam estar orientados por padrões subjetivos que limitam sua produção ao suprimento de itens que saciem as necessidades dos membros de suas famílias (Lima \& Pozzobon, 2005).

Desse modo, investigações acerca do contexto ribeirinho e da forma de produção e de subsistência utilizada por famílias que vivem às margens dos rios são importantes. Considerando, então, as características do contexto em que vivem, constitui-se como objetivo deste artigo analisar como se modificam as avaliações de mães beneficiárias do PBF moradoras de uma comunidade ribeirinha amazônica, após a inserção no programa.

\section{Método}

\section{Delineamento}

Foi realizado um estudo de casos múltiplos holístico com quatro mães beneficiárias a respeito de sua avaliação sobre o benefício que recebem. De acordo com Yin (2010), os estudos de casos múltiplos utilizam uma lógica de replicação e não de amostragem, na qual a questão base de pesquisa é replicada entre os participantes, sendo que essa replicação envolve pressuposições de similaridades ou contrastes entre os casos. Neste estudo, as participantes possuíam como característica similar o fato de serem ribeirinhas e beneficiárias do PBF.

Levantaram-se informações acerca de aspectos estruturais e socioeconômicos das famílias, bem como sobre as mudanças ocorridas após a inserção no programa. Consideraram-se tais mudanças a partir da percepção que as beneficiárias apresentaram sobre a renda do trabalho do marido, a frequência dos gastos e o suprimento de necessidades.

Em um primeiro momento, no período de março a setembro de 2011, foi desenvolvido o projeto "Dinâmica de famílias ribeirinhas e urbanas: o uso do tempo de crianças atendidas pelo Programa Bolsa Família (PBF)”, que teve como objetivo principal fazer um orçamento de atividades desempenhadas por crianças e adolescentes (participantesalvos/PA) beneficiados pelo PBF em populações urbanas e ribeirinhas da cidade de Belém, estado do Pará. Durante esse período, foram realizadas entrevistas e construiu-se um 
banco de dados de 50 famílias residentes no município, sendo 24 ribeirinhas. As famílias desse projeto foram selecionadas em função de as crianças participantes estudarem na escola com a qual foi efetivado o contato para a realização da pesquisa. Essas crianças e suas famílias residiam na Ilha do Combú. Posteriormente, para que fosse realizada a pesquisa no ambiente urbano, os mesmos procedimentos de seleção das famílias foram realizados, porém, na escola polo a que a escola ribeirinha era anexa.

\section{Participantes}

Participaram deste estudo quatro mães ribeirinhas moradoras da Ilha do Combú - Belém (PA), beneficiárias do PBF. As mães foram selecionadas após a averiguação das informações familiares contidas no banco de dados do Laboratório de Ecologia do Desenvolvimento Humano da Universidade Federal do Pará (LED/UFPA). O principal critério para a escolha das participantes foi a receptividade e a disposição das beneficiárias a participarem da pesquisa, sendo privilegiadas as que tivessem sido entrevistadas pela pesquisadora responsável por este estudo no primeiro momento da coleta de dados, realizado em 2011.

No que diz respeito às características das mães, todas mantinham um relacionamento estável e apresentavam idade de 26, 30, 31 e 50 anos. A principal ocupação das participantes era a realização de atividades domésticas, sendo que uma das participantes realizava tarefas de cabeleireira. A renda familiar per capita média era de $\mathrm{R} \$ 159,86$, variando de $\mathrm{R} \$ 80,00$ a $\mathrm{R} \$ 284,00$.

\section{Contextualização}

A pesquisa foi realizada na ilha do Combú, parte insular de Belém do Pará. Belém conta com 39 ilhas e a ilha do Combú possui uma extensão territorial de $15.972 \mathrm{~km}^{2}$, sendo a quarta maior ilha de Belém em tamanho e espaço territorial. Está situada ao sul do centro da cidade, a 6,3 km em linha reta da área central de Belém (SEGEP, 2011) (Figura 1).

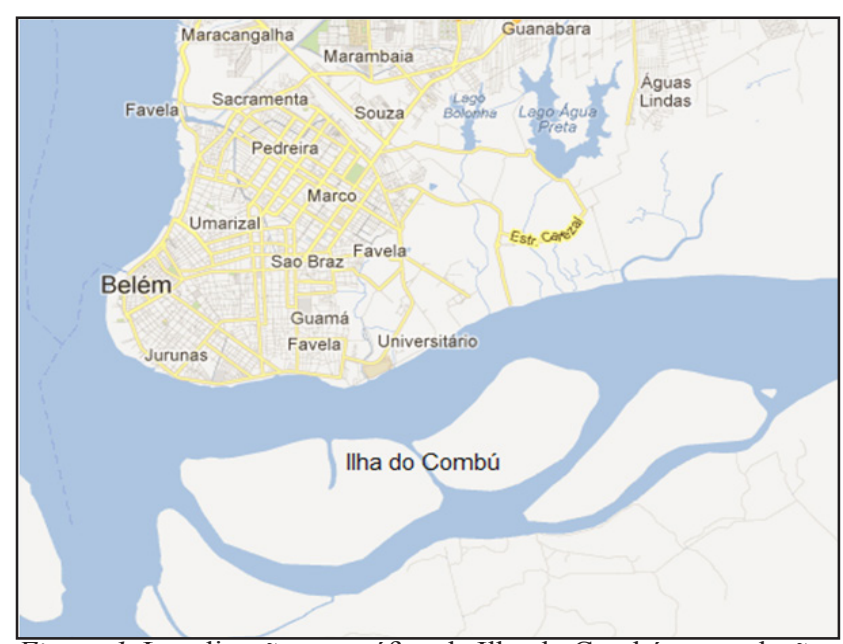

Figura 1. Localização geográfica da Ilha do Combú com relação à área urbana de Belém. Dados do mapa: Google, DigitalGlobe
De acordo com Rodrigues (2006), os ribeirinhos da ilha do Combú pertencem à categoria social da produção rural familiar, que aponta para atividades alternativas no que se refere à geração de emprego e renda. Porém, diferem das comunidades ribeirinhas que se encontram em situação de isolamento, pois a proximidade com o grande centro urbano da capital proporciona o acesso a recursos que são escassos aos ribeirinhos tradicionais, como as iminentes possibilidades de compra e venda de recursos, além de disporem de meios de comunicação que reproduzem os desejos estimulados pela mídia, favorecendo o consumo.

As moradias da comunidade são de madeira, cobertas com telhas de barro ou amianto, construídas em palafitas e distantes, aproximadamente, 30 metros umas das outras. A energia elétrica fornecida pela concessionária estadual chegou à ilha em julho de 2011. Não há tratamento de água, sendo que a água potável é obtida principalmente através da comercialização por um barqueiro e tem a procedência desconhecida pelas famílias investigadas (Afonso, Araújo, Reis, Silva, \& Pontes, 2012).

\section{Instrumentos}

Inventário biossociodemográfico. O inventário biossociodemográfico tem como objetivo obter informações estruturais acerca da família, como a estrutura familiar, idade dos participantes, ocupação e escolaridade; aspectos do domicílio, como tipo de moradia, acesso à água potável e esgotamento sanitário adequado, tempo de residência na comunidade, entre outros; e algumas características econômicas relacionadas à renda geral e ao recebimento do benefício do PBF, como valor da renda geral, os membros da família que contribuem financeiramente, o valor do benefício, a forma como foi gasto no mês anterior à entrevista, entre outras. Esse instrumento foi aplicado em todas as famílias em um primeiro momento da coleta de dados, entre julho de 2010 e janeiro de 2011, e, posteriormente, reaplicado nas quatro famílias participantes deste estudo, a fim de verificar a possível ocorrência de mudanças na estrutura familiar.

Entrevista semiestruturada. Além do inventário biossociodemográfico, foi aplicada uma entrevista semiestruturada que tinha as seguintes questões norteadoras: (a) Como era a sua vida antes de entrar para o PBF?; e (b) Como é a sua vida hoje em dia? Para responder a essas questões, foram organizados tópicos que enfatizavam as mudanças ocorridas na vida familiar após a inserção no benefício, como a forma pela qual a família obtinha recursos para suprir as necessidades básicas e como o benefício era gasto. Com relação aos hábitos de consumo, foi investigado: quanto ganhavam; o que compravam; para quem compravam; com que frequência compravam; como usavam o que compravam e as negociações dos recursos (tempo, dinheiro e esforços) de modo geral.

\section{Coleta e Análise dos Dados}

O estudo foi submetido ao Comitê de Ética em Pesquisa do Instituto de Ciências da Saúde da Universidade 
Federal do Pará, que aprovou sua execução sob CAAE 00838212.8.0000.0018. Posteriormente, foi realizada a seleção das famílias no banco de dados do LED/ UFPA.

As visitas ocorreram entre os meses de agosto e setembro do ano de 2012, sendo realizadas 2 visitas para cada família. A primeira para a aplicação do inventário biossociodemográfico e a segunda para a aplicação da entrevista com roteiro semiestruturado. A pesquisa foi realizada respeitando o processo iterativo da pesquisa qualitativa (Gibbs, 2009), no qual os pesquisadores devem, a todo o momento, alterar suas atitudes a fim de aperfeiçoar a coleta e a análise dos dados. Desse modo, temas que surgiram em entrevistas iniciais e que não haviam sido planejados foram recuperados nas entrevistas realizadas com outros participantes. Ainda seguindo a lógica de Gibbs (2009), antes da aplicação dos instrumentos na família seguinte, foi realizada a transcrição dos dados, a fim de averiguar aspectos que pudessem proporcionar informações importantes para a execução das entrevistas seguintes.

Durante a aplicação das entrevistas, as participantes estavam em suas residências realizando suas atividades comuns. Em alguns momentos, seus filhos estavam presentes e em outros, os mesmos estavam na escola. Em todas as entrevistas, o marido das participantes estava ausente. Todas as entrevistas foram realizadas e transcritas por uma psicóloga, que, à época, estava realizando o estudo para produzir sua dissertação de Mestrado, sendo que, a cada contato com as famílias, foi realizada uma reunião com outra psicóloga, doutora e professora universitária, para discutir questões referentes ao processo de coleta de dados.

Após a aplicação e transcrição de todos os instrumentos, foi realizada uma análise de conteúdo qualitativa dos dados (Bardin, 1977) a fim de estabelecer categorias para as falas das participantes de modo êmico, ou seja, com as categorias sendo produzidas a posteriori (Gibbs, 2009). Os nomes utilizados são fictícios, a fim de manter a identidade dos participantes preservada.

\section{Resultados e Discussão}

A compreensão da avaliação das mães beneficiárias acerca das modificações ocasionadas após a participação no PBF é fundamental, pois, de acordo com Lunt (1996), a compreensão econômica de uma situação deve passar pela percepção que as pessoas têm da mesma. A partir da análise das entrevistas, foi possível depreender mudanças na avaliação das participantes acerca das categorias: renda do marido, frequência dos gastos e suprimento das necessidades.

\section{Renda do Marido Antes e Após o PBF}

O trabalho realizado pelo marido na extração e venda do açaí era a principal fonte de renda de todas as famílias. Entretanto, houve uma modificação da percepção do rendimento gerado por essa atividade antes e após a entrada da família no PBF. Antes da participação no PBF, o dinheiro obtido pelo marido era a única fonte de renda da família e era obtido quase exclusivamente pela extração do açaí.
Desse modo, possuía uma importância fundamental para as beneficiárias, o que pode ser notado na seguinte fala: Tudo dependia dele, do meu esposo, do trabalho dele, porque tem o mato, dai que era a renda (Inês - Família 2).

Esse rendimento provinha de um trabalho informal, sujeito à sazonalidade e à disponibilidade dos frutos, diferente do que ocorre com o dinheiro do PBF, considerado como uma renda estável, com a qual é possível realizar planos, como pode ser observado na seguinte fala:

Mas aí, de repente, até mesmo se a gente tem uma prestação pra gente pagar [...], de uma coisa de necessidade, de casa mesmo...

$A i$, às vezes, não tem aquele dinheiro que coisa, quer dizer que a gente já tem um dinheiro que é certo, né? Ai, já dá pelo menos pra gente tirar ou a metade, alguma coisa. (Inês - Família 2)

$\mathrm{O}$ elemento de sazonalidade provoca maior insegurança com relação ao suprimento das necessidades da família, que é uma das principais características de pessoas pobres acerca de sua condição (Underlid, 2007). De acordo com Underlid (2007), ao investigar a percepção de insegurança de 25 beneficiários de programas sociais noruegueses, a pobreza e seus fatores correlacionados conferem a essas pessoas um senso de insegurança, ao qual os respondentes reagiam com apreensão e ansiedade.

Quando questionadas acerca dessa mesma renda após a entrada no PBF, as esposas identificaram apenas aspectos do trabalho, como a quantidade de vezes que os mesmos iam vender o açaí por semana e o preço das rasas (quantidade específica de açaí, equivalente a um balde médio) de açaí vendidas. Porém, não houve mais nenhuma referência a uma exclusividade desse dinheiro para a manutenção da família.

De acordo com Yin (2010), para compreender o sentido do que os participantes expressam, é necessário atentar também para as ausências de referências a determinado tema, através de frequentes comparações entre os casos. A ausência de uma referência à renda do trabalho do marido como a única fonte de provimentos financeiros da família, com toda a importância atribuída a esse fato, pode denotar que as participantes compreendem que, após a entrada no PBF, houve uma mudança qualitativa, e não apenas quantitativa, no orçamento familiar.

A importância do atual dinheiro recebido pelo programa também é expressa pelas modificações que esse rendimento proporcionou, reconhecidas pelas mães como as possibilidades de poupança e de aquisição de bens materiais. Tais aquisições e poupanças não eram possíveis quando havia apenas o rendimento do marido uma vez que este era destinado principalmente para o suprimento das necessidades de alimentação.

Que se eu bem pensasse, a gente tinha bem as coisas aqui em casa. Se eu guardasse o dinheiro e pegasse, por exemplo, guardasse dois meses, [...] já dava pra eu comprar uma coisa melhor pra ele. (Débora - Família 3)

Olha, eu tinha só um colchão, né? Depois que eu recebi o Bolsa Família, eu comprei mais um. Os meninos dormiam tudo um por cima do outro. [...] Ai, televisão, eu comprei uma pequena e ganhei uma também da minha colega lá em Belém. (...) Antes do Bolsa Família não tinha. (Noêmia - Família 1)

A sazonalidade da produção do açaí e o fato de o rendimento proveniente desse recurso ser obtido diariamente 
também ocasionaram a dificuldade em realizar um cálculo exato acerca do dinheiro obtido em um mês.

Acho que o meu esposo recebe uns 500... uns 600 reais, eu acho. Isso porque é safra, né? (...) Porque, assim, é tão variado que, às vezes, não tem nem uma coisa, assim, certo pra dizer assim. (Inês - Família 2)

Outro elemento que também dificultava a contabilidade mensal da renda era a aquisição e utilização do dinheiro obtido com o açaí ser realizada diariamente. Desse modo, o marido trazia os alimentos e produtos necessários à família assim que obtinha algum rendimento, o que também afetava a frequência dos gastos familiares.

Nota-se, então, que o dinheiro proveniente da extração do açaí foi percebido de maneiras distintas antes e após a inserção no programa. As participantes relataram que, antes da participação no PBF, havia uma extrema dependência da renda do marido para a subsistência da família. Considerando que, em todas as falas das participantes, as mesmas não percebiam esse dinheiro como lhes pertencendo, sendo referido sempre como o dinheiro "dele", possivelmente havia uma condição na qual o marido controlava sozinho o destino do dinheiro.

\section{Frequência dos Gastos Antes e Após o PBF}

Como consequência da sazonalidade do açaí, um dos elementos de grande destaque na avaliação das participantes foi a diferença da frequência dos gastos realizados pela família. Com relação ao período anterior à entrada no programa, uma das mães relatou o seguinte:

Às vezes, a gente guardava pra fazer compra só no final de semana. Mas quando não tinha nada, a gente tinha que gastar todo dia. Todo dia que eu vendia e comprava, vendia e comprava. (...) Era mais difícil de guardar. Era só mesmo pra vender e comprar, vender e comprar. (Noêmia - Família 1)

De acordo com as participantes, as compras eram realizadas à medida que havia necessidade e dinheiro disponível, sendo geralmente feitas diariamente. Após a entrada no PBF, houve a diminuição da necessidade de compras diárias, sendo essas reservadas apenas para compra de alimentos que pereciam mais rápido, como as carnes. Os outros itens referentes à alimentação eram comprados semanalmente, quinzenalmente ou mensalmente.

Desse modo, é possível afirmar que, antes da inserção das famílias no PBF, havia maior insegurança alimentar, já que, na ausência do açaí, a família não possuía recursos financeiros que suprissem suas necessidades. Após a participação no programa, houve maior possibilidade de planejamento e, consequentemente, de controle dos gastos, pois os mesmos passaram a ser feitos semanal ou mensalmente, o que provavelmente ocasionou maior segurança alimentar. A frequência dos gastos, então, estava ligada diretamente à possibilidade de maior controle da economia familiar, além de possibilitar o suprimento das necessidades básicas da família.

\section{Suprimento de Necessidades Antes e Após o PBF}

A renda obtida através da participação no PBF afetou consistentemente a aquisição de elementos que satisfazem as necessidades dos membros familiares. Antes de receberem o benefício, as participantes afirmaram que o dinheiro do orçamento familiar não era suficiente para supri-las. As participantes foram questionadas a respeito da existência de situações nas quais não houvesse alimento para sua família, sendo que uma das participantes respondeu o seguinte: Já! Já passou sim. Vez que não tinha nada mesmo. Acabava tudo. Não tinha café, leite, bolacha, não tinha farinha, não tinha nada. Passamos. É (Noêmia - Família1).

Quando questionadas acerca de quanto tempo durava essa escassez ou dificuldade, as participantes afirmaram que o período de maior escassez de recursos não durava muito, sendo de, no máximo, dois dias. Com relação às atitudes tomadas diante dessas situações, as respostas foram as seguintes:

Ah, às vezes, eu pegava fiado, e, às vezes, o irmão dele dava alguma coisinha assim pras meninas comerem. (Noêmia Família 1)

A gente sempre pedia ajuda de Deus, né, que desse pra gente todo dia, né. Que desse condições pra gente comprar. (...) Ai, já vinha, ficava esperando os dias pra receber, né? Ai já iam tiravam um fiado... (Inês - Família 2)

As respostas estavam centradas no auxílio de pessoas da família, o que é recorrente no caso de comunidades mais tradicionais, como as ribeirinhas, que se caracterizam também pela eminência da pobreza (Silva, Pontes, Lima, \& Maluschke, 2010), na obtenção de crédito em estabelecimentos comerciais e no apelo à religiosidade. $\mathrm{O}$ apoio de pessoas próximas com as quais seja estabelecido um vínculo de confiança e reciprocidade é muito utilizado por famílias pobres como recurso para assegurar sua sobrevivência e bem-estar (Fontes \& Eichner, 2004). Em termos financeiros, a existência de contas em estabelecimentos comerciais, ou "fiados", também é típica de ambientes empobrecidos economicamente, nos quais seja necessário existir confiança entre os membros (Brussi, 2012). Por fim, a religiosidade e o desenvolvimento espiritual são importantes fatores de proteção para o enfrentamento de adversidades, sendo fundamentais no estabelecimento de crenças que favoreçam processos de resiliência individual e familiar (Walsh, 1996).

Considerando a vulnerabilidade econômica dessas famílias, os elementos mencionados pelas participantes são fatores de proteção, ou seja, são elementos que "têm a função de interagir com os eventos de vida e acionar processos que possibilitem incrementar a adaptação e a saúde emocional" (Poletto \& Koller, 2008, p.408). De acordo com essas autoras, a rede de suporte social e a religiosidade são elementos muito importantes para o enfrentamento de situações de vulnerabilidade.

No que diz respeito à suficiência da renda atual para o suprimento das necessidades da família, as respostas das participantes direcionaram para uma maior suficiência do dinheiro obtido, apesar da persistência de dificuldades financeiras. Quando questionadas especificamente acerca 
das mudanças ocorridas após a entrada no PBF, as respostas foram as seguintes:

Tem dia assim que acaba o dinheiro e falta, assim, alguma coisa. Ai eu não tenho nenhum centavo às vezes pra comprar. Mas, é dificil assim. É raro assim, faltar, sabe? (...) É mais raro do que antes. (Noêmia - Família 1)

Portanto, houve melhoria da situação econômica após a entrada no PBF, pois, apesar de ainda existirem situações nas quais não há dinheiro para comprar alimentos, tais situações eram mais raras. Um elemento que foi ressaltado nas respostas das participantes é que o dinheiro obtido era suficiente quando se consideravam as necessidades básicas de sobrevivência, sem ponderar a compra de bens como eletrodomésticos ou móveis para a casa.

De maneira geral, o dinheiro do benefício foi visto de maneira oposta ao dinheiro da extração do açaí, que estava sujeito a disposições temporais, como os períodos de safra e entressafra e a disponibilidade diária do produto. Diante dessas características, tornava-se mais difícil realizar planejamentos sobre o dinheiro do açaí, sendo que o mesmo não ocorria com o dinheiro do benefício, que era caracterizado pela maior estabilidade. Tratava-se de uma renda previsível e, portanto, passível de planejamento e que proporcionava, consequentemente, maior sensação de segurança.

Esses resultados vão ao encontro do trabalho de Silva (2011), para quem o PBF contribui para a redução da insegurança alimentar entre os beneficiários, promovendo o acesso regular e permanente a alimentos. Segundo esse autor, houve um aumento significativo da duração e da disponibilidade dos alimentos nas residências, de modo que houve uma diminuição no número de famílias que comiam menos ou deixavam de comer pela ausência de alimentos.

\section{Considerações Finais}

O PBF é uma estratégia de combate à pobreza e às mazelas decorrentes dessa situação, que possui grande amplitude e importância na vida econômica e social de seus beneficiários. A perspectiva pessoal desses atores sociais é um dos fatores que deve ser considerado na avaliação das estratégias utilizadas pelo poder público para beneficiar os cidadãos. A Psicologia Econômica, com o pressuposto da necessidade de compreender a forma como as pessoas entendem as situações econômicas que vivenciam, contribui para a integração teórica das informações provenientes da avaliação dos beneficiários do programa. A partir da análise das modificações na avaliação das participantes após a entrada no PBF, é possível compreender a maneira como estas entendem o benefício que recebem e a sua importância para o bem-estar da família.

Para as famílias ribeirinhas investigadas, houve uma modificação na sua situação econômica após a inserção no programa. De maneira geral, o benefício é a única alternativa ao dinheiro proveniente do trabalho do marido, sendo mais estável, pois há uma data exata na qual as mesmas o receberão. Como consequência, houve uma alteração na frequência dos gastos domésticos, que não estão mais sujeitos exclusivamente à disponibilidade da renda do marido e a maior possibilidade de planejamento e controle das despesas domésticas.

Porém, dadas as características metodológicas deste estudo, foram encontradas algumas limitações e dificuldades, como o acesso às participantes, uma vez que as mesmas residiam em contexto ribeirinho, que demanda transporte específico para acesso às residências e dificuldade de contato telefônico constante. Além do mais, a presença de um pesquisador demanda um período de adaptação para que seja estabelecida uma relação de confiança e as participantes sintam-se mais à vontade. Esse período também é custoso em função das características geográficas, uma vez que ocorreram situações em que foi necessário voltar mais de duas vezes às residências, pois as participantes estavam ausentes nos momentos que haviam sido combinados para a realização das entrevistas.

Como limitações metodológicas e sugestões para estudos futuros com relação ao tema, é necessário que esta amostra seja expandida e que insira métodos variados para compreender como o dinheiro é avaliado. Essas amostras podem incluir beneficiários urbanos e residentes em outros contextos especiais de proteção social, como quilombolas e indígenas, outros membros da família e participantes com condições diferentes das encontradas pelas respondentes deste estudo, como mães solteiras e recasadas, além de avós e outros familiares responsáveis pela criança beneficiária.,

O estudo das percepções de beneficiários de um programa de transferência de renda com a magnitude do PBF em contextos específicos, distintos do ambiente urbano, é fundamental em termos de promoção de políticas direcionadas a características específicas de beneficiários, com o aumento da possibilidade de a política atingir seus objetivos. As informações sobre a forma como as pessoas avaliam o benefício que recebem são importantes para o planejamento e avaliação das políticas públicas, pois possibilitam a análise da eficiência e da eficácia das ações. Cabe ao Estado disponibilizar serviços que alcancem os usuários, proporcionando-lhes maior autonomia e senso crítico da realidade, além de condições para as quais se desenvolvam de maneira saudável.

\section{Referências}

Afonso, T., Araújo, M. E. C., Reis, D. C., Silva, S. S. C., \& Pontes, F. A. R. (2012). Programa Bolsa Família: Uma análise dos aspectos sociodemográficos e das rotinas de crianças nos contextos urbano e ribeirinho amazônico (Relatório enviado ao Ministério do Desenvolvimento Social e Combate à Fome). UFPA, Belém.

Albuquerque, F. J. B. (2002). Psicologia Social e formas de vida rural no Brasil. Psicologia: Teoria e Pesquisa, 18(1), 37-42. doi: 10.1590/S0102-37722002000100005

Bardin, L. (1977). Análise de Conteúdo (L. A. Reto \& A. Pinheiro, Trad.). Lisboa, Portugal: Edições 70.

Brussi, J. D. E. (2012). Negócios \& dádivas: Relações de mercado em um contexto de reciprocidade. Campos, 13(2), 39-53. 
Castro, H. C. O., Walter, M. I. M. T., Santana, C. M. B., \& Stephanou, M. C. (2009). Percepções sobre o Programa Bolsa Família na sociedade brasileira. Opinião Pública, 15(2), 333-355. doi: http://dx.doi.org/10.1590/S0104-62762009000200003

Cruz, V. C. (2008). O rio como espaço de referência identitária: Reflexões sobre a identidade ribeirinha na Amazônia. In S. C. S.Trindade Júnior \& M. G. C. Tavares (Eds.), Cidades ribeirinhas na Amazônia: Mudanças e permanências (pp. 4967). Belém: EDUFPA.

Ferreira, V. R. M. (2008). Psicologia Econômica: Como o comportamento econômico influencia nas nossas decisões. Rio de Janeiro: Elsevier.

Fontes, B. A. S-M., \& Eichner, K. (2004). A formação do capital social em uma comunidade de baixa renda. REDES-Revista Hispana para el Análisis de Redes Sociales, 7(2), 1-33.

Gibbs, G. (2009). Análise de dados qualitativos (R. C. Costa, Trans.). Porto Alegre: Artmed.

Kahneman, D. (2012). Rápido e devagar: Duas formas de pensar (C. A. Leite, Trans.). Rio de Janeiro: Objetiva.

Kirchler, E. (1999). Household decision making. In P. Earl \& S. Kemp (Eds.), The Elgar Companion to Consumer Research and Economic Psychology (pp. 296-304). Aldershot: Edward Elgar.

Kooreman, P. (2000). The labeling effect of a child benefit system. The American Economic Review, 90(3), 571-583. Recuperado de http://www.jstor.org.ez3.periodicos.capes.gov. br/stable/117343

Haddad, M. (2008). Bolsa Família and the needy: Is allocation contributing to equity in Brazil? Journal of International Development, 20(5), 654-669. doi: 10.1002/jid.1445.

Lima, D. \& Pozzobon, J. (2005). Amazônia socioambiental. Sustentabilidade ecológica e diversidade social. Estudos Avançados, 19(54), 45-76. Recuperado de http://www.scielo. br/pdf/ea/v19n54/03.pdf

Lunt, P. (1996). Discourses of savings. Journal of Economic Psychology, 17(6), 677-690. doi: http://dx.doi.org/10.1016/ S0167-4870(96)00035-9

Ministério do Desenvolvimento Social e Combate à Fome. (2012, dezembro 20). Bolsa Família (website). Recuperado de http:// www.mds.gov.br/bolsafamilia

Ministério do Desenvolvimento Social e Combate à Fome. (2014, setembro 11). Boletim O Brasil Sem Miséria no Seu Município - Belém-PA. Recuperado de http://www.brasilsemmiseria.gov. br/municipios

Moura, E. A. F., Nascimento, A. C., \& Côrrea, D. S. S. (2007). "Cesta Básica" (rancho) das populações ribeirinhas da Amazônia. Cadernos de Saúde Coletiva, 15(4), 517-530. Recuperado de http://www.iesc.ufrj.br/cadernos/images/ csc/2007_4/artigos/CSC_IESC_2007_4_6.pdf

Pires, A. (2008). Bolsa Família e políticas públicas universalizantes: O caso de um município paulista. Cadernos de Pesquisa, 38(134), 341-366. doi: http://dx.doi.org/10.1590/S010015742008000200005

Poletto, M., \& Koller, S. H. (2008). Contextos ecológicos: Promotores de resiliência, fatores de risco e de proteção. Estudos de Psicologia (Campinas), 25(3), 405-416. doi: http:// dx.doi.org/10.1590/S0103-166X2008000300009
Programa das Nações Unidas para o Desenvolvimento. (2010). Relatório de Desenvolvimento Humano 2010: A verdadeira riqueza das nações: vias para o desenvolvimento humano. Recuperado de http://hdr.undp.org/en/media/HDR_2010_PT_ Complete_reprint.pdf

Reis, D. C., Araújo, M. E. C., Santos, S. S. L., Silva, S. S. C., \& Pontes, F. A. R. (2012). Araraiana e Combú: Um estudo comparativo de dois contextos ribeirinhos amazônicos. Temas em Psicologia, 20(2), 429-438. doi: 10.9788/TP2012.2-11

Rodrigues, E. T. (2006). Organização comunitária e desenvolvimento territorial: o contexto ribeirinho em uma ilha da Amazônia (Unpublished master's thesis). Universidade Federal do Pará, Belém. Recuperado de http:/www.ufpa.br/naea/gerencia/ ler_tcc.php?id=40-

Secretaria Municipal de Coordenação Geral do Planejamento e Gestão. (2011). Anuário Estatístico do Municipio de Belém v. 16. Recuperado de http://www.belem.pa.gov.br/app/ ANUARIO_2011/ANUARIO\%202011\%20COMPLETO.pdf

Silva, D. A. (2011). Sobrepeso e obesidade em crianças de cinco a dez anos de idade beneficiárias do Programa Bolsa Família no estado do Sergipe, Brasil. Revista Paulista de Pediatria, 29(4), 529-535. doi: http://dx.doi.org/10.1590/S010305822011000400010

Silva, S. S. C., Pontes, F. A. R., Lima, L. C., \& Maluschke, J. B. (2010). Rede social e papeis de gênero de casais ribeirinhos de uma comunidade amazônica. Psicologia: Teoria e Pesquisa, 26(4), 605-612. doi: http://dx.doi.org/10.1590/S010237722010000400004

Silva, S. S. C., Pontes, F. A. R., Santos, T. M., Maluschke, J. B., Mendes, L. S. A., Reis, D. C., \& Silva, S. D. B. (2010). Rotinas familiares de ribeirinhos amazônicos: uma possibilidade de investigação. Psicologia: Teoria e Pesquisa, 26(2), 341-350. doi: http://dx.doi.org/10.1590/S0102-37722010000200016

Soares, F. V., Ribas, R. P., \& Osório, R. G. (2010). Evaluating the impact of Brazil's Bolsa Família. Latin American Research Review, 45(2), 173-190. doi: 10.1353/lar.2010.0017

Underlid, K. (2007). Poverty and experiences of insecurity. A qualitative interview study of 25 long-standing recipients of social security. International Journal of Social Welfare, 16, 65-74. doi: 10.1111/j.1468-2397.2006.00423.x

van Raaij, W. F. (1999). Economic Psychology between Psychology and Economics: An introduction. Applied Psychology, 48(3), 263-272. doi: 10.1111/j.1464-0597.1999.tb00001.x

Walsh, F. (1996). The concept of family resilience: Crisis and challenge. Family Process, 35(3), 261-281. doi: 10.1111/j.15455300.1996.00261.x

Yin, R. K. (2010). Estudo de caso: Planejamentos e métodos (4 ed). Porto Alegre: Bookman.

Recebido em 03.06.2013

Primeira decisão editorial em 10.03.2015

Versão final em 23.03.2016

Aceito em 23.06.2016 